\title{
The Evolution and New Dynamics of Interpreting Studies
}

\author{
SU Jiangli \\ Shanxi University, Taiyuan, China
}

\begin{abstract}
Through four periods of development, interpreting studies have become an established research area. Examining the landmarks of its growth and factors contributed to its healthy development, this article concludes that practitioners' researches have laid a strong foundation for the debut and outburst of interpreting studies, but, interdisciplinarity and cooperation will broaden the horizon of interpreting studies and invest vitality to ensure its prosperity.
\end{abstract}

Keywords: evolution, interpreting studies, interdisciplinarity, cooperation

\section{Introduction}

Interpreting has been used to facilitate communication across different languages and cultures throughout the history of humanity. Interpreting as a form of interlingual mediation can be dated back to 3000BC when ancient Pharaohs of Egypt carried out interactions with his counterparts in Asia, Europe, and Africa. But it was not until the 20th century that interpreting as known today emerged as a profession. According to Herbert (1978), the 1919 Peace Conference in Paris in the wake of the World War I witnessed the birth of conference interpreting as French ceased to be the lingua franca of international diplomatic negotiations. The 1928 International Labor Organization Conference and especially the Nuremberg Trail marked the origin of simultaneous interpreting. Thus, during the 1930s interpreting became a recognized and established profession. However, research into Interpreting Studies started to appear in the late 1950s. Pochhacker and Shlesinger (2002) state that even the term interpreting studies itself only came into existence in 1992 when it was first used by Gile at the Translation Studies Congress in Vienna, and by Salevsky at the 8th Conference on Translation and Interpreting at Charles University, Prague. Even if it is a relatively young field of scientific inquiry with regard to old age of the actual practice, it began to bloom in the late half of the 20th and flourishes in the 21st century in the soil of multi-discipline and climate of post modern in social science studies. This article will summarize the evolution of interpreting studies, examine major issues of interpreting studies, and discuss the landmarks in interpreting research and factors contributed to its growth. Based on these points, this article will point out the new dynamics essential to the prosperity of interpreting studies.

\section{The Evolution of Interpreting Studies}

Danile Gile divides the development of interpreting research in the west into four periods: the pre-research, experimental psychology, practitioners', and renewal or renaissance periods (1994, pp. 149-152).

\section{The Pre-research Period}

According to Gile, the essential characteristic of this period is that production was based on speculation

SU Jiangli, M.A., Associate Professor, School of Foreign Languages, Shanxi University, Taiyuan, China. 
and personal experience rather than scientific or academic research. But this budding period identified most of the fundamental issues which are still discussed (1994, p. 153).

\section{The Experimental Psychology Period}

The period between the 1960s and early 1970s is characterized by studies based on experiments carried out by such psychologists and psycholinguists as Treisman, Oleron and Nanpon, Goldman-Eisler, Gerver, etc. During this period, a number of hypotheses were formulated regarding the interpreting process and the influence of other factors like the source language, noise, speed of speech delivery, but the validity or representativeness is often doubtful. Pochhacker and Shlesinger believe that the most prominent figure in this period is Gerver who conducted experiments on various factors that could affect the capacity of the interpreter's short-term memory or simultaneous interpreting performance such as intonation, stress, noise, and source language presentation rate which have later formed basis for many studies by various researchers of different orientations (2002, p. 27). The credit for the first to develop a complete information-processing model of simultaneous interpreting should also be given to Gerver.

\section{The Practitioners' Period}

From the early 1970s to the mid-1980s, the practitioners, mainly professional interpreters and teachers of interpreting began to take over the field of interpreting studies. A number of models were put forward to account for the interpreting process including Danica Seleskovitch's theory of sense which achieved unprecedented predominance in the field of interpreting research during this period and has been influencing the training of interpreters and the theoretical conception of the interpreting process ever since. The importance of the model as a pedagogical tool can hardly be over-estimated. It helps training interpreters to concentrate on what people say instead of the words they are using. Schools around the world have been training interpreters according to strategies developed from the ideas put forward by the model. However, Gile (1990) argued that there was little empirical evidence, experimental or observational to support hypotheses.

\section{The Renaissance Period}

Gile names the period between late 1980s and onward a renaissance because it is in this period that the earlier calls for scientific, empirical, and interdisciplinary investigation and cooperation have been seriously echoed by practitioners. The cooperation between researchers and practitioners as well as between researchers has been increasing at a large scale. The practitioners have become more open-minded and began to borrow ideas from translation studies and cognitive science to expand their horizons.

\section{Five Major Issues of Interpreting Research}

During the four above mentioned periods, researchers have conducted their research through personal meditation, psychological experiments, theoretical frameworks, and multidisciplinary perspectives. But they mainly concerned themselves with five major issues. They are cognitive, language, profession, quality, and training issues.

\section{Cognitive Issues}

Motivated by the mystery of the mental processes that lie beneath the activity of simultaneous listening and speaking, psychologists and psycholinguists are committed to accounting for the interpreting process from a cognitive perspective. Cognitive researches have been mostly process-oriented. Researchers mainly focus on bilingualism, attention, comprehension, memory, production, and interpreting strategies. 


\section{Language Issues}

The command of language is of vital importance to interpreting. So, language classification, language direction, and linguistic abilities and language teaching in interpreting training are always researchers' major concerns.

AIIC (International Association for Conference Interpreters) divides interpreters' working languages into active and passive languages. Active languages are languages into which interpreters work and can be either of the two kinds: A language and $\mathrm{B}$ language. A passive or $\mathrm{C}$ language is a language which the interpreter can fully understand and one of which she/he interprets into the active languages.

One of the most important purposes of examination for assessing students' interpreting aptitude and acceptance to training program is to test the candidate's linguistic abilities and command of his/her working languages because knowledge of language is a prerequisite to interpreting. This view is upheld by AIIC as one of its training criteria. That's why some researchers and institutes insist on jump-starting the training programs without sufficient language teaching. However, some scholars argue that it is true that the students should come to the course with a full mastery of the working language but it's a serious mistake to take it for granted that they will know the language the way they really should.

Literally, the controversy is not over language teaching in training programs but over which interpreting training model is more efficient to follow. Some prefer the postgraduate model—they tend to devote the whole course to interpreting techniques and skills and discard language teaching since the duration of up to two years does not allow for too many things to be crammed into the course.

\section{Professional Issues}

Issues related to the professional interpreting are always researchers' concern. Such issues include interpreters' knowledge and specialization, provision of documentation, technical working conditions, workload, fatigue and stress, and interpreters' social status.

\section{Quality Issues}

The debate over interpreting quality is still an unresolved issue due to the elusiveness of the concept of quality (Pochhacker and Shlesinger ed., 2002). AIIC has set up a screening system whereby each candidate for membership of AIIC should be recommended by five competent members who will observe him/her in real situations before the candidate is given admission to AIIC.

Researchers have approached the quality issues largely from two perspectives: the criteria for evaluating interpreting quality and factors that could negatively affect interpreting quality.

\section{Training Issues}

With the increasing demand for highly qualified interpreters training issues come to the foreground in interpreting research.

The importance of training can be seen in the development of criteria of rating and quality for interpreting training programs such as the criteria of best practice set by AIIC and the EMCI (European Masters in Conference Interpreting) consortium which was set up in 2001.

The researches conducted are mainly related to such areas as student selection and aptitude testing, interpreter training curricula, theoretical components in interpreter training programs and training exercises and training procedures. 


\section{Landmarks in Interpreting Studies}

\section{Danica Sleskovitch and the Theory of Sense}

The epoch-making theory developed by the founder of Paris School Sleskvotich has brought revolutionary change to interpreting studies and teaching. The theory of sense was based on the idea of Herbert, who stressed that interpreting should not be seen as a mere linguistic transcoding-literal translation of each segment-but rather a process of comprehension and reformulation (Schjoldager, 1994, p. 77). Seleskovitch absorbed Herbert's idea of reformulation but proposed that it had to be preceded by a step of deverbalization.

According to Salama-Carr, the starting point of the theory is the distinction it makes between explicitness and implicitness, where the former refers to what speakers say and the latter to what they actually intend to say (2007). Sense is the combination of both. The basic point of the theory lies in that language comprehension is a dynamic process that occurs whenever units of linguistic meaning are merged with extralinguistic knowledge to make sense. Thus, they believe interpreting is a three-stage process: (1) listening, (2) deverbalization, and (3) reproduction of sense. The extralinguistic knowledge is seen as cognitive complements, that is, the knowledge of world that changes language meanings onto interpreter's meaning or sense. Cognitive complements refer to verbal, situational, and cognitive contexts and encyclopedic knowledge. Cognitive complements interact with units of meaning to make sense, thus allowing for comprehension of the incoming message and identification of the intended interpretation of the original.

Deverbalization refers to the process during which source languages lose their linguistic shape within three or four seconds of reception and change into a non-verbal sense in the interpreter's mind. Therefore, it is not linguistic meanings, but deverbalized sense that makes it possible for the interpreter to come up with natural and spontaneous expression in target language. The production process involved in interpreting is not a direct conversion of the source language to the target language; it's rather a conversion from the source language to cognitive sense and an expression of this sense in target language. This clear cognitive separation between the source language and target language provided by deverbalization plays a significant role in helping eliminate any possible linguistic interference which more often than not results in linguist borrowing of source language structures and expressions.

Even if there can be no doubt for the merits of this theory "as a didactic tool when students have to rid themselves of their word fixation. Critics have repeatedly pointed out that this theory is at best a tentative hypothesis that has never been empirically verified” (Schjoldager, 1994, p. 77). But, lacking scientific validation has not stopped it from being successfully applied to the teaching of interpreting and gaining predominance as the largely undisputed leader in interpreting theory. With hindsight, Pochhaker argues that "Seleskovith ushered in what Gile perceives as both a promising initial phase in interpreting research and theory and, due to a lack of systematic analysis of empirical data, a subsequent period of stagnation” (1995, p. 32).

\section{Experiments Carried Out by Behavioral and Cognitive Scientists}

French psychologists, Pieer Oleron first conducted experiments to study simultaneous interpreting process. And British psychologists, Frieda Goldman-Eisler studied pause of interpreters to screen the information processing of interpreting. More importantly, Gerver, professor of Oxford University, attempted to establish information-processing model to examine interpreters’ information processing in real situations. 
However, the works of these researchers who were not practicing interpreters themselves were fiercely opposed by many in the interpreting community and their results were often accused of lacking validity for the reality interpreting.

\section{Practitioners' Participation}

Practitioners began to participate in interpreting research and several models were proposed. What's more, it led to the formation of Leipzig School, Former Soviet School, and Paris School, which greatly boosted the research and teaching of interpreting.

\section{Interdisciplinarity and Cooperation}

Interdisciplinarity, cooperation and descriptive methodology, this new approach was heralded at the 1986 Trieste Symposium held in University of Trieste, Italy. The conference on the Theoretical and Practical Aspects of Teaching Interpreting aimed at presenting the lasted findings of neurophysiologic experiments and studies on lateralization of language in bilinguals and polyglots, studying and assessing aptitude tests for would-be student interpreters, comparing teaching methods with non-European training schools and motivating further research to encourage researchers to exchange information and experience. Participants of this interdisciplinary gathering not only included researchers from other fields like psychology, neuroscience but also interpreting practitioners from other parts of the world such as the former Soviet Union and Japan. This allowed comparison and exchanging ideas between practitioners and researchers of other fields. Gile believes this openness has resulted in actual multidisciplinary interpreting research and ushered the beginning of a new era in the evolution of interpreting studies, "the Trieste Era” (1994, p. 151). A case in point is neuroscientific studies in interpreting on shared attention, memory and recall, lateralization, roles of ears.

\section{Factors That Contributed to the Growth of Interpreting Studies}

A number of factors combined contributed to the development of interpreting studies. The following are the most important ones.

\section{Degree and Research Training Program}

First and foremost is the establishment of degree and research training programs in interpreting at some universities, which have given rise to the production of a large number of MA theses and doctoral dissertations since some of them have lasting influence on the field.

The impact of these training and research programs on the growth of interpreting studies has become more pronounced as some of the interpreting schools have come to be seen as centers of excellence by researchers of interpreting studies worldwide. Among the most well-known are Paris School, which introduced the first doctoral studies in translation and interpreting in 1974 and has strengthened the theoretical foundation of interpreting and the Trieste School which is specifically renowned for its interest in interdisciplinary research.

\section{Conferences}

Conferences have provided opportunities for researchers from different parts of the world and research orientations to meet, discuss, and exchange ideas. Some conferences can be considered as landmarks in the history of interpreting studies such as the 1977 NATO Symposium, 1986 Symposium in Trieste, and the 1994 Turku International Conference on Interpreting, The Forli Conference and American Translators Association's Annual Conference. 


\section{Publication of Interpreting Journals}

Interpreting journals open the channels for communications among researchers. Some of the well-known journals include The Interpreters' Newsletter, Interpreting, Babel, Target, Forum, Meta, The Translator, AIIC Bulletin.

\section{New Dynamics in Interpreting Studies}

1. According to Gile, a clear trend that emerges from recent publications and from the exchanges emerged during the Turku conference is that a more scientifically oriented paradigm is continuing to gain weight among interpretation investigators (1995, p. 16). In terms of new technology such as voice recognition, big data, and machine translation, Gile believes high technology and innovation allow researchers to get access to lots of data and offer new, powerful ways to process data (Wang, 2018, pp. 54-56).

2. A number of studies conducted by practice researches concerning linguistics and neurolinguistics for example research conducted by Shlesinger and Daro.

3. One type of interdisciplinary research is interpreters working closely with non-interpreters. This trend is particularly salient in the University of Trieste.

4. Another example of multidisciplinary is the bulk of studies on interpreting drawing on such translation studies as text linguistics, discourse analysis, and text typology (Pochhacker, 1995, p. 55).

5. Intercultural mediation is a new trend in interpreting studies which according to Pochhacker and Shlesinger has been first raised by Kirchhoff who has discussed the difficulty of interpreting texts with a distinct source language orientation. Her interpreting model has been explored by Kondo and Dam (2002, p. 96).

6. Pochhacker takes the functionalist angel to critically develop the skopos theory proposed by Hans J. Vermeer (1995, p. 31).

7. Some scholars are advocating the sociological and cultural turn of interpreting studies. They borrow theoretical foundations and critical methodologies from cultural and sociological studies to conduct interpreting studies from the perspectives of gender, ethnic, post-colonial, and post modern.

8. The forming of interpreting research centers has promoted interpreting studies and led to the prosperity of interpreting studies. These research centers include Paris, Trieste, Vienna, and Georgetown. Paris has been the most important research center in Europe, though the influence of Paris University III is gradually fading. Lyon University becomes more and more influential because of the impact of productive Professor Gile and the compilation and publication of The IRN Bulletin. Trieste University is famous for its empirical and scientific interdisciplinary research. It boasts such forerunners of interdisciplinary studies as Gran and Fabbro. It also publishes high profile academic journal Interpreters' Newsletter. Department of Translator and Interpreter Training, University of Vienna established its place in interpreting studies largely because of the contribution of Professor Ingrid Kurz. Interpretation and Translation School of Georgetown University has also ranked among the heartlands of interpreting research due to ground breaking studies conducted by Professor David Bowen and Margareta Bowen (Xiao, 2002, pp. 74-75).

9. Interpreting studies conducted by Chinese, Japanese, and South Korean researchers have contributed to and enriched interpreting studies and broken the dominance of western especially European scholars (Wang, 2019, p. 24). 


\section{Conclusion}

As a young field of scientific inquiry, interpreting studies established itself as a significant research area because of the revolutionary theoretical frameworks built by practitioners. And it gained new momentum from interdisciplinary studies and cooperation between interpreters and non-interpreters. Cooperation and interdisciplinarity have invested new vigor into the field and the formation of a number of research centers will ensure the prosperity of interpreting studies in the future.

\section{References}

Gile, D. (1990). Research proposal for interpreters. In L. Gran and C. Taylor (Eds.), Aspects of applied and experimental research on conference interpretation (pp. 226-236). Udine: Campanotto Editore.

Gile, D. (1994). Methodological aspects of interpretation and translation research. In S. Lambert and B. Moser-Mercer (Eds.), Bridging the gap: Empirical research in simultaneous interpretation (pp. 39-56). Amsterdam: John Benjamins Publishing Company.

Gile, D. (1995). Interpreting research: A new impetus? Hermes, Journal of Linguistics, (14), 15-19.

Herbert, J. (1978). How conference interpretation grew. In D. Gerver and H. W. Sinaiko (Eds.), Language interpretation and communication (pp. 5-10). Boston, MA: Springer.

Pochhacker, F. (1995). Simultaneous interpreting: A functionalist perspective. Hermes, Journal of Linguistics, (14), 31-54.

Pochhacker, F., \& Shlesinger, M. (Eds.). (2002). The interpreting studies reader. London: Routledge.

Salama-Carr, M. (2007). Translating and Interpreting Conflict. Leiden, Netherlands: Brill.

Schjoldager, A. (1994). Interpreting research and the manipulation school of translation studies. Hermes, Journal of Linguistics, (12), 65-89.

Wang, B. H. (2019). The construction of interpreting theories based on interpreting cognition. Chinese Translators Journal, (1), 19-29.

Wang, X. (2018). An interview with Professor Gile: The new dynamics and new trends. East Journal of Translation, (5), 52-56.

Xiao, X. Y. (2002). Interpreting research in the west: A critical analysis of its history and current status. Journal of Foreign Languages, (4), 71-76. 